\title{
EFFECTS OF WORKING ENVIRONMENT ON ISCHEMIC HEART DISEASE BURDEN PROFILE IN YOUNG EGYPTIAN MALES
}

\author{
By \\ ${ }^{1}$ Negm H, ${ }^{1}$ Fayez M, ${ }^{2}$ El Mahdy N, ${ }^{3}$ Youssef A \\ ${ }^{I}$ Cardiology \& Ultrasonography Unit of the Egyptian Academy of Scientific Research and Technology. \\ ${ }^{2}$ National Egyptian Center of Environmental \& Toxicological Research Faculty of Medicine, Cairo University. \\ ${ }^{3}$ Middle East Medicare - Health Maintenance Organization
}

\begin{abstract}
Introduction: Ischemic Heart Diseases (IHD) are mostly attributed to increased exposure to traditional risk factors. Few studies were directed to understand the environmental and occupational determinants as potentially modifiable risk factors. Aim of work: To evaluate the impact of various working environments on the ischemic heart disease burden profile in young Egyptian male workers. Materials and Methods: Three years follow up of ischemic events in three groups of workers based on the type of industry was performed. Group I (Motor industry) which included 4779 individuals, group II (Construction industry) which included 6230 individuals \& group III (Food industry) which included 2613 individuals. Main risk factors analysis were collected from out-patient visits and investigations results, followed by multicenter in time on site monitoring on groups records of in-patient admissions and different interventional coronary procedures performed. Results: Mean age in motor industry group was $34.6 \pm$ 9 , in construction group was $35.8 \pm 9$ while in food industry group was $31.6 \pm 7$. Total incidence of coronary artery disease in the three groups was $1.5 \%$; of hypertension $4.3 \%$; of diabetes mellitus $3.5 \%$ and that of dyslipidemia was $2.3 \%$. Incidence of coronary events in motor industry was significantly higher than the other two industries. Highly significant increase in number of total in-patient and critical care admissions due to acute coronary syndromes and myocardial infarction in addition to number of interventional coronary procedures was observed in motor and construction industries when compared to food industry. Conclusion: Different working environmental hazards might increase the incidence of coronary artery diseases in young Egyptian male workers either directly or through augmenting known risk factors. Morbidity due to IHD might be affected by the type of industry. Cooperation between general practitioners, occupational diseases specialists and cardiologists may improve the efficiency of prevention programs.
\end{abstract}

Key words: Ischemic Heart Disease (IHD), Traditional risk factors, Occupational risk factors, Type of industry, Prevention programs. 


\section{Introduction}

Cardiovascular diseases (CVDs), an important cause of morbidity and premature mortality worldwide, are due to a constellation of modifiable and nonmodifiable risk factors - some known and others unknown (Prasad et al., 2010).

In developed countries, CVDs were an important health issue a long time ago but in developing countries did not pose a major problem as compared with communicable diseases and malnutrition (WHO 1998).

However, the trend of CVD epidemic today has diversified in two contrasting directions. In developed countries, the epidemic of CVD is decreasing as a result of great efforts spent on identification of major risk factors and taking necessary interventions (Murray and Lopez 1997). Meanwhile, in developing countries, CVDs and its related risk factors have emerged as a major challenge for public health (Liu 2007) and consequently have been identified as a priority area for health researches (Minh et al., 2003).

Traditional risk factors for CVDs are hypertension, hypercholesterolemia, hyperuricemia, diabetes mellitus, smoking, obesity, type A personality, males, physical inactivity and heredity (Prasad et al., 2010)
The relationship between adverse working conditions and CVDs has been investigated for many decades, including studies on the effect of physical workload, noise, long working hours, shift work and social job characteristics (Backe et al., 2012).

Working environmental factors are traditionally subdivided into physical, chemical, biological and psychological factors that often act concomitantly and which, together with lifestyle factors and genetic predisposition, are the background for the development of most of the occupational diseases. In addition to being a direct cause of disease, working environment factors can also enhance the development of these diseases (Juel et al., 2008).

The increasing burden of chronic cardiovascular diseases had an enormous impact on population health, the health care system and the economy. The need for a better understanding of how to slow down the processes of cardiovascular disease generation and progression, and how to improve preventive and therapeutic strategies is obvious in populations with increased numbers of premature cardiovascular diseases (Greiser et al., 2005). 


\section{Aim of Work}

To evaluate the impact of working environment in three different industries, on ischemic heart disease burden profile in young Egyptian male workers.

\section{Materials and Methods}

\section{Study population:}

This observational study was conducted over a period of 3 years starting from January 2008 to December 2010 in 3 different industries including:

- Group I (Motor Industry) which included 4779 individuals.

- Group II (Construction industry) which included 6230 individuals.

- Group III (Food industry) which included 2613 individuals.

- All workers are young males aged from 18 to 45 years old.

- Exclusion criterions are workers above 45 years old, those previously diagnosed with heart problems or with history of previous related medications, those with family history of cardiovascular and cerebrovascular events.

- A field visit was performed to the 3 factories to identify different exposures in each industry.

\section{Study Methods:}

General practitioner (GP) clinics in the factory had been used for follow up of workers 3 times /week. First visit included:

1. Careful history taking including name, age, social status, special habits.

2. Presence of any previous illnesses or symptoms suggesting the presence of heart disease as chest pain, dyspnea on exertion, palpitation, easy fatigability.

3. Presence or absence of any traditional risk factors.

4. Family history of hypertension, diabetes or dyslipidemia or any other illnesses.

5. General examination was performed including vital signs, chest, heart and abdominal examinations.

6. Laboratory investigations were performed including fasting and postprandial blood sugar, serum urea and creatinine, lipid profile and electrocardiographic assessment and chest $\mathrm{x}$-ray.

- General Practitioner was referring emergency cases for diagnostic or therapeutic cardiac procedures for admission, interference and reporting in time in addition to following patients admitted from emergency unit of any hospital daily. 
- Daily follow up for inpatients during their stay in hospital were reported.

- Discharged patients were followed up in outpatient clinics and factory clinics.

- All data had been stratified for each industry and subjected to statistical analysis.

\section{Statistical analysis:}

Statistics were done by computer using MedCalc version 12 - (C) 1993-2011 The tests used were:

1. Incidence rate of ischemic heart disease or any cardiovascular risk factors were calculated by incidence.

2. Comparison between incidences of heart disease or any cardiovascular risk factors using $\mathrm{T}$ test for rate comparison.

3. Spearman correlation coefficient test (1): to test for linear relation between 2 numeric variables (Sahai and Khurshid, 1996).

- Significant result is considered if $\mathrm{P} \leq$ 0.05 .

- Highly significant result is considered if $\mathrm{P} \leq 0.005$.

- Very high significant result is considered if $\mathrm{P} \leq 0.001$.

\section{Results}

- The age of the studied population ranged from 18 to 45 years old in the 3 industries.

- Working hours ranged from 8-12 hours per day for 5 days/week.

- All workers included in the study didn't have any traditional risk factors before employment.

- Workers were diagnosed with hypertension based on the average of up to three BP measurements with an average systolic blood pressure $(\mathrm{SBP}) \geq 140 \mathrm{mmHg}$ or an average diastolic BP (DBP) $\geq 90$ $\mathrm{mmHg}$ or currently using BP-lowering medication (CDC, 2012).

- Workers were diagnosed with diabetes or dyslipidemia according to related investigations.

- Results were traced from multicenter in time on site monitoring of group records including in-patient admissions, coronary care unit admissions, diagnostic coronary angiography, interventional coronary procedures and coronary artery bypass surgeries.

$\square$ Mean age in Motor Industry group was $34.6 \pm 9$, in Construction group was $35.8 \pm 9$ while in Food Industry group it was $31.6 \pm 7$. 
$\square$ Total incidence of Coronary Artery Disease in the three groups was $1.5 \%$.

$\square$ Total incidence of Hypertension was 4.3 $\%$. (Table 1)

$\square$ Total incidence of Diabetes Mellitus in the three groups was $3.5 \%$ while total incidence of Dyslipidemia was $2.3 \%$. (Table 1)

$\square$ Incidence of coronary events in Motor Industry was significantly higher than the other two industries $(\mathrm{P} \leq 0.05$ from Construction Industry \& $\mathrm{P} \leq 0.0001$ from Food Industry) (Table4). $\square$ Incidence of coronary events in Construction Industry was significantly higher than Food Industry ( $\mathrm{P} \leq 0.0003)$ (Table 4).

Very highly significant increase in number of total in-patient, cardiac care unit admissions; in addition to number of interventional coronary procedures "diagnostic and therapeutic" were observed in Motor Industry and Construction Industry when compared to Food Industry (P $\leq 0.0001)$ (Table 4).

Table (1): Incidence of traditional risk factors in all Groups

\begin{tabular}{|c|c|c|c|c|c|c|c|c|c|}
\hline & Total & HTN & Incidence & DM & Incidence & DYS & Incidence & $\begin{array}{c}\text { Total } \\
\text { risk } \\
\text { factors }\end{array}$ & Incidence \\
\hline $\begin{array}{c}\text { Motor } \\
\text { Industry }\end{array}$ & 4779 & 269 & $5.63 \%$ & 177 & $3.70 \%$ & 159 & $3.33 \%$ & 448 & $9.37 \%$ \\
\hline $\begin{array}{c}\text { Construction } \\
\text { Industry }\end{array}$ & 6230 & 261 & $4.19 \%$ & 239 & $3.84 \%$ & 131 & $2.10 \%$ & 451 & $7.24 \%$ \\
\hline $\begin{array}{c}\text { Food } \\
\text { Industry }\end{array}$ & 2613 & 63 & $2.41 \%$ & 68 & $2.60 \%$ & 28 & $1.07 \%$ & 137 & $5.24 \%$ \\
\hline \begin{tabular}{c} 
All groups \\
\hline
\end{tabular} & 13622 & 593 & $4.35 \%$ & 484 & $3.55 \%$ & 318 & $2.33 \%$ & 1036 & $7.61 \%$ \\
\hline
\end{tabular}

HTN : Hypertension

DM: Diabetes Mellitus

DYS : Dyslipidemia 


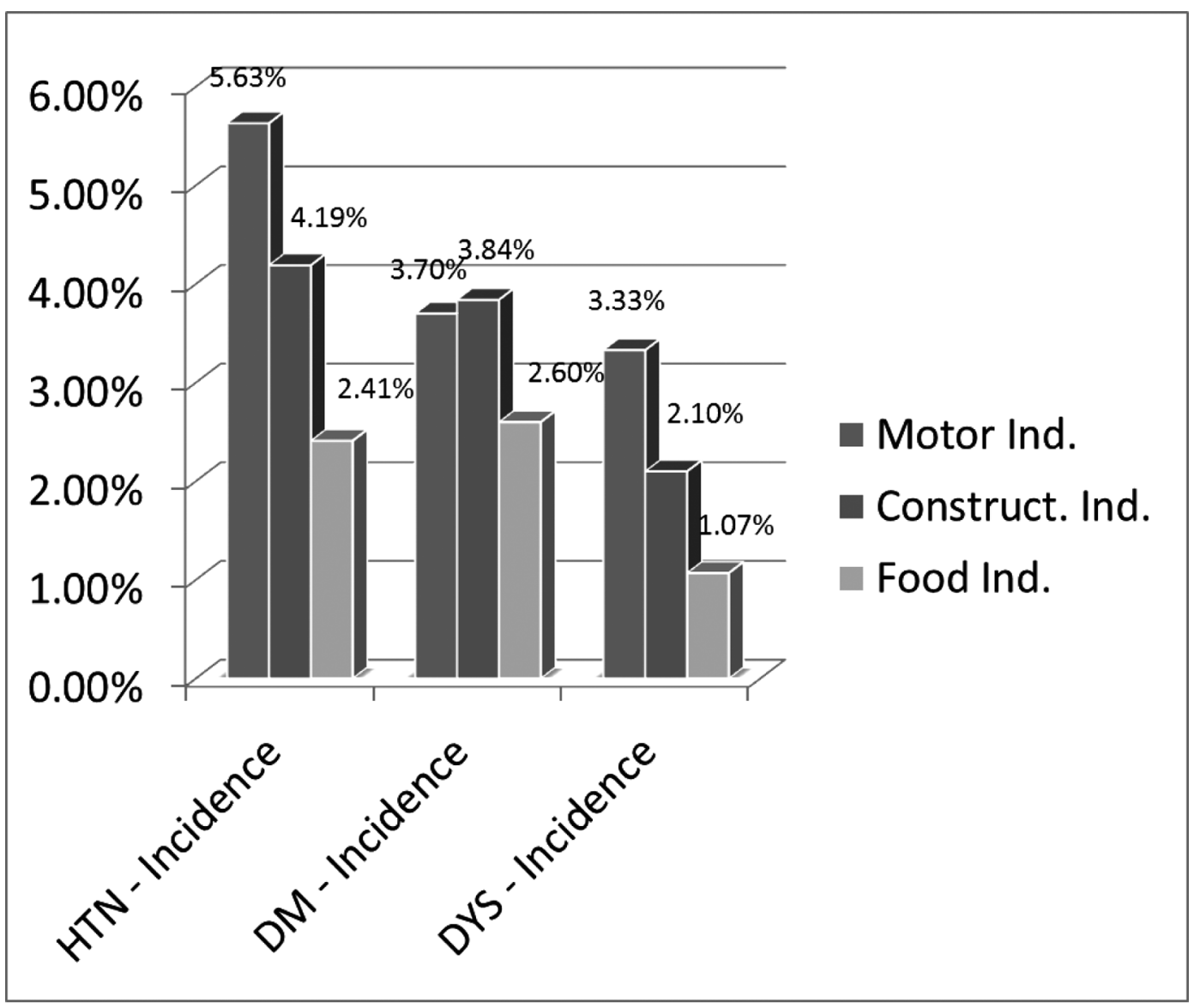

Figure (1): Incidence of traditional risk factors in all groups 
Table (2): Incidence of IHD, Coronary Care Unit admissions (CCU) admissions \& Cardiac interventions in all groups.

\begin{tabular}{|c|c|c|c|c|c|c|c|}
\hline Industry & Total & IHD & Incidence & $\begin{array}{c}\text { CCU } \\
\text { admissions }\end{array}$ & Incidence & $\begin{array}{c}\text { Therapeutic } \\
\text { Cardiac } \\
\text { intervention }\end{array}$ & Incidence \\
\hline Motor & 4779 & 81 & $\% 1.69$ & 74 & $\% 1.55$ & 20 & $\% 0.42$ \\
\hline Construction & 6230 & 106 & $\% 1.70$ & 71 & $\% 1.14$ & 29 & $\% 0.47$ \\
\hline Food & 2613 & 16 & $\% 0.61$ & 9 & $\% 0.34$ & 8 & $\% 0.31$ \\
\hline All groups & 13622 & 203 & $\% 1.49$ & 154 & $\% 1.13$ & 57 & $\% 0.42$ \\
\hline
\end{tabular}

IHD: Ischaemic Heart Diseases

CCU: Coronary Care Unit

Table (3): Cardiac Interventions in all groups:

\begin{tabular}{|c|c|c|c|c|c|c|c|}
\hline \multicolumn{2}{|c|}{ Industries } & \multicolumn{2}{c|}{ Motor Industry } & \multicolumn{2}{c|}{ Construction Industry } & \multicolumn{2}{c|}{ Food Industry } \\
\hline \multicolumn{2}{|c|}{ Interventions } & No. & $\%$ & No. & $\%$ & No. & $\%$ \\
\hline \multicolumn{2}{|c|}{ Diagnostic CA } & 24 & 0.50 & 29 & 0.47 & 5 & 0.19 \\
\hline \multicolumn{2}{|c|}{ Therapeutic cardiac interventions } & 20 & 0.42 & 29 & 0.47 & 8 & 0.31 \\
\hline \multirow{2}{*yyyyyyyy}{} & Per metal stent & 8 & 0.17 & 9 & 0.14 & 4 & 0.15 \\
\cline { 2 - 9 } & Drug eluting & 5 & 0.10 & 11 & 0.18 & 2 & 0.08 \\
\cline { 2 - 9 } & Balloon dilatation & 4 & 0.08 & 2 & 0.03 & 0 & 0.00 \\
\cline { 2 - 9 } & CABG & 3 & 0.06 & 7 & 0.11 & 2 & 0.08 \\
\hline \multicolumn{2}{|c|}{ Total cardiac interventions } & 44 & 0.92 & 58 & 0.93 & 13 & 0.50 \\
\hline
\end{tabular}

Diagnostic CA: Coronary angiography

CABG: Coronary artery bypass grafting

Table 3 shows that the number of diagnostic CA was higher in Motor Industry, followed by Construction Industry then the least was in Food Industry.

The same pattern was observed in number of cardiac intervention including balloon dilatation, pre metal stent, drug eluting stent \&CABG which indicate the observation of more significant lesions in coronary arteries in Construction and Motor industries when compared to Food industry.

Drug eluting stents are used more for left main coronary vessels at bifurcations and in diabetic patients.

CABG had been used in patients with 3 vessel diseases or left main coronary stenosis. 
Table (4): Comparison between the incidence rate in the 3 groups:

\begin{tabular}{|c|c|c|c|c|c|c|}
\hline & \multicolumn{2}{|c|}{$\begin{array}{c}\text { Motor Industry \& } \\
\text { Construction Industry }\end{array}$} & \multicolumn{2}{c|}{$\begin{array}{c}\text { Motor Industry \& } \\
\text { Food Industry }\end{array}$} & \multicolumn{2}{c|}{$\begin{array}{c}\text { Construction Industry \& } \\
\text { Food Industry }\end{array}$} \\
\hline & $\begin{array}{c}\text { Incidence } \\
\text { rate } \\
\text { difference }\end{array}$ & P-value & $\begin{array}{c}\text { Incidence } \\
\text { rate } \\
\text { difference }\end{array}$ & P-value & $\begin{array}{c}\text { Incidence } \\
\text { rate } \\
\text { difference }\end{array}$ & P-value \\
\hline $\begin{array}{c}\text { Coronary } \\
\text { Events }\end{array}$ & 0.003692 & $\mathrm{P} \leq 0.050$ & 0.008656 & $\mathrm{P} \leq 0.0001$ & 0.004964 & $\mathrm{P} \leq 0.0003$ \\
\hline $\begin{array}{c}\text { CCU } \\
\text { Admissions }\end{array}$ & 0.004088 & $\mathrm{P} \leq 0.0504$ & 0.01204 & $\mathrm{P}<0.0001$ & 0.007952 & $\mathrm{P} \leq 0.0003$ \\
\hline $\begin{array}{c}\text { Cardiac } \\
\text { Interventions }\end{array}$ & -0.0001659 & $\mathrm{P} \leq 0.9303$ & 0.00465 & $\mathrm{P} \leq 0.0324$ & 0.004816 & $\mathrm{P} \leq 0.0239$ \\
\hline $\begin{array}{c}\text { Cardiac Inp. } \\
\text { Services }\end{array}$ & -0.0002857 & $\mathrm{P} \leq 0.9243$ & 0.01509 & $\mathrm{P} \leq 0.0001$ & 0.01537 & $\mathrm{P} \leq 0.0001$ \\
\hline
\end{tabular}

Inp.: Inpatients

Coronary events: means the occurrence of sudden cardiac death or a confirmed fatal or nonfatal myocardial infarction, diagnosed by ECG and/or cardiac enzyme changes (Kip et al., 2008). 
Table 5: Correlation between traditional risk factors \& cardiac inpatient services:

\begin{tabular}{|c|c|c|c|}
\hline Correlation & $\begin{array}{l}\text { Motor Risk - } \\
\text { Motor Inp. }\end{array}$ & $\begin{array}{c}\text { Cons.Risk - } \\
\text { Cons.Inp. }\end{array}$ & $\begin{array}{c}\text { Food Risk - Food } \\
\text { Inp. }\end{array}$ \\
\hline Correlation coefficient $\mathbf{r}$ & 0.6842 & 0.7851 & 0.4912 \\
\hline Sample size & 4778 & 6230 & 2614 \\
\hline \multirow{2}{*}{$95 \%$ Confidence interval for $r$} & 0.6689 & 0.7754 & 0.4616 \\
\hline & 0.699 & 0.7944 & 0.5198 \\
\hline Significance level & $P \leq 0.0001$ & $\mathrm{P} \leq 0.0001$ & $\mathrm{P} \leq 0.0001$ \\
\hline
\end{tabular}

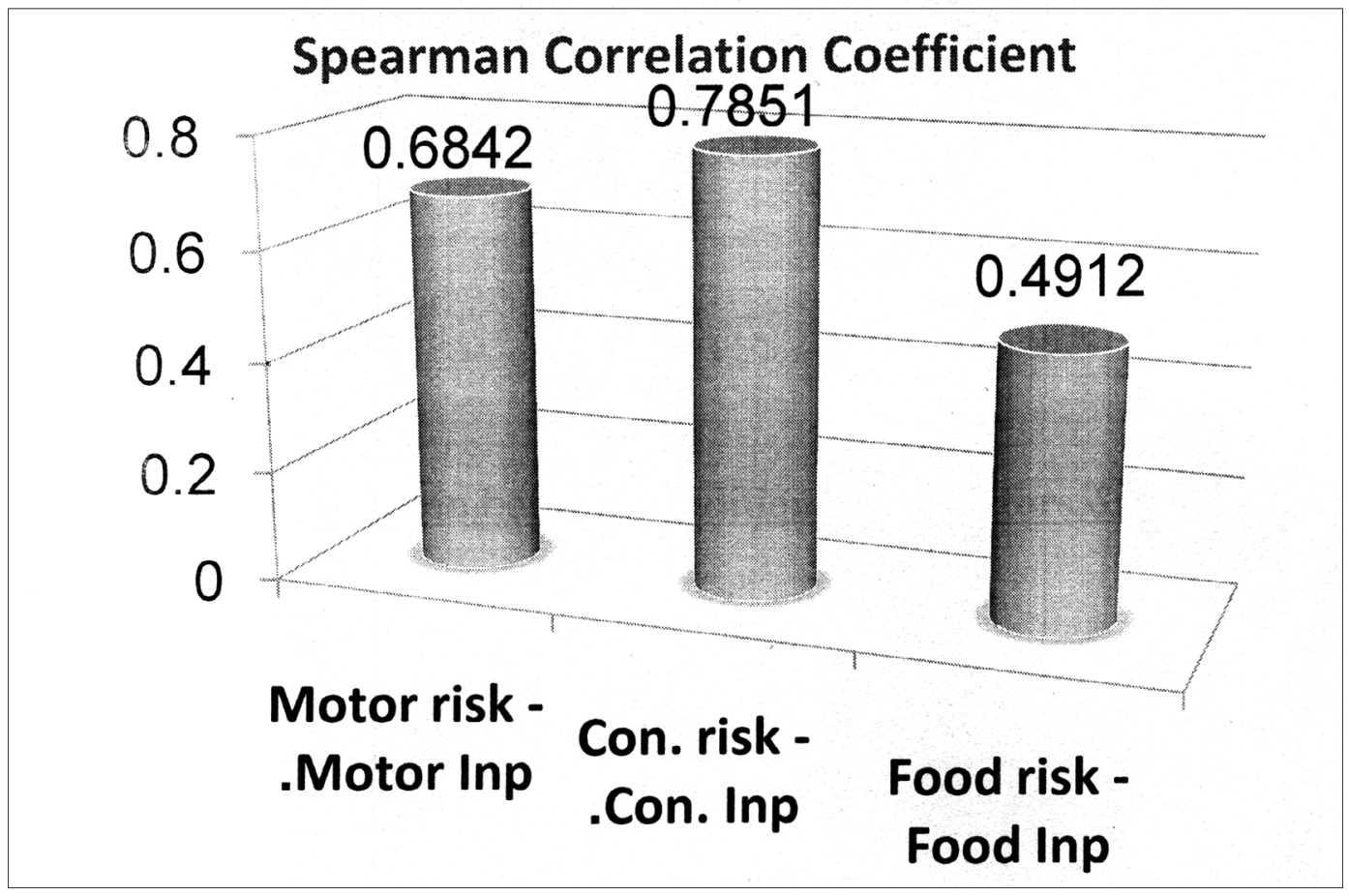

Figure (2): Correlation between traditional risk factors $\&$ cardiac inpatient services:

SCC: Spearman Correlation Coefficient

Con. Inp: Construction Inpatients
Motor Inp: Motor Inpatients

Food Inp: Food Inpatients 
Table 5 and Figure 2 showed that there was very highly significant correlation between the number of traditional risk factors \& cardiac inpatient services.

Construction Industry

Motor Industry

Food Industry

$$
\begin{aligned}
& \text { SCC }=0.7851, \mathrm{P} \leq 0.0001 \\
& \text { SCC }=0.6972, \mathrm{P} \leq 0.0001 \\
& \text { SCC }=0.4912, \mathrm{P} \leq 0.0001
\end{aligned}
$$

However the correlation between traditional risk factors \& cardiac inpatient services in construction industry was very highly significantly correlated than the other 2 industries

\begin{tabular}{|c|c|c|c|}
\hline Industry & Physical & Chemical & Psychological \\
\hline Motor Industry & $\begin{array}{l}\text { Electricity, } \\
\text { Vibration, Noise. }\end{array}$ & $\begin{array}{l}\text { Paint solvents (toluene, ketones, } \\
\text { mineral spirits, xylene, ethyl } \\
\text { glycol...etc), Binders (resins), } \\
\text { Dyes, Chromates, Organic } \\
\text { nitrates.Asbestos fibres . } \\
\text { Isocyanates } \\
\end{array}$ & $\begin{array}{l}\text { Poor working } \\
\text { conditions, long } \\
\text { working hours, } \\
\text { job stress, work } \\
\text { load, poor working } \\
\text { conditions, }\end{array}$ \\
\hline $\begin{array}{l}\text { Construction } \\
\text { Industry }\end{array}$ & $\begin{array}{l}\text { Tough } \\
\text { environments } \\
\text { (noise, vibration, } \\
\text { handling of cargo } \\
\text { and direct exposure } \\
\text { to fluctuating } \\
\text { weather) }\end{array}$ & \begin{tabular}{|l} 
Dusts(asbestos - silica - cement \\
- wood dust). Metals (cadmium- \\
copper, lead, chromium, \\
zinc, nickel, magnesium). \\
Solvents (benzene - toluene, \\
trichloroethylene, methylene \\
chloride). Others (epoxy resins \\
- isocyanates, formaldehyde). \\
Organic nitrates \\
\end{tabular} & $\begin{array}{l}\text { Violence, } \\
\text { poor working } \\
\text { conditions, } \\
\text { long working } \\
\text { hours, unsteady } \\
\text { employment, stress }\end{array}$ \\
\hline Food Industry & Noise, heat & $\begin{array}{l}\text { Food additives, packaging } \\
\text { materials }\end{array}$ & $\begin{array}{l}\text { Job stress, long } \\
\text { working hours }\end{array}$ \\
\hline
\end{tabular}
$(\mathrm{P} \leq 0.0001)$.

Table (6): Types of exposures among the 3 tested industries:

Table (6) shows the different exposures in the three industries which could contribute to increased incidence of CVDs in young age group. 


\section{Discussion}

Many diseases may affect workers which could be partially aggravated due to occupational exposure .These diseases are known as "work related diseases". It can be difficult to identify a causal relationship because the effect of the initial exposure, which could be very limited, and the onset of symptoms occurring much later. Thus the results obtained in the various studies do not reflect the degree of exposure to harmful substances at the time of the study, but rather the result of exposure that began many years earlier (Juel et al., 2008).

In our study, we tried to investigate the role of different occupational exposures in causation of CVD in young workers. The study design and method were not able to avoid the traditional risk factors which were common in nearly all the studied groups.

The differences which were found between the three groups examined in our study are probably work-related; work environment might unveil or enhanced some of those cases.

It is evident in that although the correlation of traditional risk factors to inpatient admissions were significantly less in Motor Industry when compared to Construction Industry (figure 2). Yet acute cardiac events were more observed in Motor Industry which open the way for the research related to non-traditional or occupational risk factors (Table 2).

We will try to discuss different factors to which workers were exposed and their contribution to the occurrence of CVDs.

\section{Effects of exposure to Psychosocial stress:}

Psychosocial stress (PSS) has been identified as a common probable additive stimulus behind premature incidence of CAD in the studied groups in general with probable minor variations between the three groups.

Psychosocial stressors are common in the 3 tested industries with a varying degree. The Construction Industry which is plagued by occupational risky situations characterized by continual changes, the use of many different resources, poor working conditions, unsteady employment, tough environment (including different physical $\&$ chemical exposures) (Pinto et al., 2011). In Motor and Construction Industries, the employees experienced monotonous highpaced work with little control over the pace or methods of work.

The relationship between ischemic heart disease and a number of psychosocial factors in the working environment has been demonstrated in a number of previous epidemiological studies. 
The study conducted by Yan and colleagues in 2003 had concluded that high intensity mental stress might be a trigger of transient myocardial ischemia, myocardial infarction (MI), ventricular arrhythmia and sudden cardiac death.

Also Backe and his colleagues in 2012 performed a systematic review on numerous publications. They found statistically significant associations between psychosocial stress and cardiovascular diseases in 14 out of 26 publications.

Among agreement with our results the studies of Kivimaki and his colleagues in 2002 and 2006 who tested the validity of two main work stress models in a single working population. They found that employees reporting high job strain and high effort-reward imbalance had a twofold higher risk of death from cardiovascular disease than their colleagues scoring low in these dimensions. In these studies initially healthy employees were adjusted for baseline variation in smoking, sedentary lifestyle, blood pressure, serum total cholesterol, body mass index, and history of diabetes and resulted in no or only a minor attenuation of hazard ratios.

However, high job strain and high effort-reward imbalance were associated with increased cholesterol concentration and body mass index at follow up. These associations may reflect pathophysiological changes related to the development of cardiovascular disease.

In agreement also Diène and colleagues in 2012 who searched through several Medline databases and concluded that besides the 'classic' cardiovascular risk factors (high blood pressure, dyslipidemia, metabolic syndrome and diabetes), the work environment is playing an increasingly significant role in cardiovascular morbidity and mortality. This conclusion came in accordance with our results. The authors attributed this effect to two complementary mechanisms. A direct mechanism that posits a chronically hyperactive sympathetic nervous system with a rise in BP and left ventricular hypertrophy, hypercatecholamineamia, an alteration in immune and inflammatory response and early onset of atherosclerosis. The indirect mechanism involves behavioral factors such as obesity, lack of physical activity, tobacco consumption and lack of access to health care or metabolic syndrome. The premise is that psychosocial factor in the workplace contribute to weakening self- control which in turn encourages an unhealthy life style with increased consumption of tobacco and a tendency to become overweight or obese.

Our results agree with Netterstrøm and Kristensen in 2005 who have demonstrated 
that work pressures such as long working hours, low decision latitude in the work situation and night work are all factors known to enhance the risk of ischemic heart disease independently of the conventional risk factors.

In contrast, another study done by Rasul and his colleagues in 2005 who used an epidemiological community study with hospital admissions data to examine if any association is explained by existing illness. They found that the association of psychological distress with an increased risk of five year CHD risk in men could be a function of baseline physical illness but an effect independent of physical illness could not be ruled out.

The study of Tsutsumi and colleagues in 2011demonstrated a significantly increased susceptibility to incident stroke among men with high strain jobs (combination of high job demand and low job control) who were nearly three times more likely to suffer from a stroke than men with low strain jobs (combination of low job demand and high job control).

Since most of the studies investigated cardiovascular diseases as a whole, it was not possible to evaluate whether work stress acts differently in relation to myocardial infarction, angina pectoris, hypertension or stroke within the same study population.
At the same time, not all people under PSS have the same somatic response and the causes of the PSS related to occupations are heterogeneous (Backe et al., 2012).

\section{Effects of exposure to Noise:}

The harmful effects of noise on human health have been underestimated for a relatively long time. This may be due to the fact that noise endangers human health in an indirect manner, as opposed to other harmful substances in the workplace or environment (Berglund et al., 2000).

Noise acts as an environmental stressor. Acute noise exposure activates responses from the autonomic and endocrine systems, leading to temporary changes in the body, such as increased blood pressure, increased heart rate and vasoconstriction (Berglund et al., 2000). After prolonged exposure, susceptible individuals in the general population may develop permanent health effects, which can reveal themselves ten to fifteen years after the time of exposure in different functional systems (Niemann et al., 2006).

In our study, exposure to noise is common in the 3 industries with different levels, we couldn't specify which industry exerted higher levels as this depends upon several factors including measurable level and duration of exposure, but our 
observation showed that differences in the level of exposures appeared in reported cases of hypertension and IHD which were more evident in Construction followed by Motor then Food industries (Table 1,2).

In accordance with our study, Attia and colleagues in 2004 studied the effects of chronic occupational noise exposure and found an association with hypertension and increased incidence of cardiovascular morbidity and mortality.

The study of Forgari and colleagues in 2001 revealed that chronic noise exposure triggered a cascade of neuroendocrine events leading to transient increase in systolic and diastolic pressures and heart rate in exposed workers less than age 50 . These changes over time might lead to permanent changes, a finding which was detected in our study.

An important research by Leather and his colleagues in 2003 studied the interaction between noise and psychosocial stress at work and concluded that the physical characteristics of an environment might not be stressful in themselves; they might act to exacerbate or attenuate the negative impact of some co-occurring psychosocial stress. Thus, where both noise and job strains are at their highest, so coping resources are likely to be most severely taxed and depleted.
Hence, it is here that the negative impact on job satisfaction, organizational commitment and self-reported health is found to be greatest.

In our study, we should also refer to the high level of recorded dyslipidemia in the 3 studied groups and if we related it to the noise effect it could be explained being higher in both Motor and Construction Industries when compared to the Food Industry where the level of noise exposure is expected to be higher in the 2 first industries (Table 1). This dyslipidemia might be caused by several factors but we couldn't deny the effect of noise on blood lipids. This finding was in accordance with the study of Attia and colleagues in 2004 who found disturbed serum lipids among noise-exposed workers with statistical significant difference between the exposed and controls.

Also, Obelenis and Malinauskiene in 2007 confirmed that noise as a chronic stressor causes the imbalance in the central and vegetative nervous systems. Noise increases catecholamine and cholesterol concentration in blood, has an effect on plasma lipoprotein levels, increases heart rate, arterial blood pressure and risk of myocardial infarction. 


\section{Exposure to Dust \& Particulate Matter (PM):}

Table (5) listed different exposures in the 3 studied groups. In our study, no available data about the exact concentration and sizes of particulate matter. Data about exposure estimation is obtained from workers and confirmed from industrial hygienists. Construction workers move continuously, each worker's position in relation to exposure sources changes often. Also, workers in a given trade do not perform the same tasks each day. It is therefore difficult to anticipate all the substances and degrees of exposure an individual may encounter on a given day or in a career. So, we tried to overview health effects related to different particle sizes.

Regarding this issue, Yang and Omaye in 2009 stated that the health effects of particulate matter (organic and inorganic materials) are significant for short-term and long-term exposures, particularly those containing several metals and silicatederived constituents that can be cytotoxic to lung cells.

It was suggested that these effects occur through direct or indirect mechanisms of action; directly through direct particle entry into the vasculature and indirectly through PM deposition on the alveoli causing a low degree of inflammation which, in turn, releases bioactive substances into the bloodstream causing coagulation of the blood and tissue damage in subjects with previous cardiovascular problems (Timothy et al., 2012).

The results of the study performed by Sharman and colleagues in 2002 on a group of automobile mechanics exposed to high levels of automotive pollution revealed that regular exposure to automotive pollutants increases plasma susceptibility to oxidation and might, in the long-term, increase the risk of developing atherosclerosis. This finding shared in explaining increased incidence of hypertension in young workers in Motor and Construction Industries in our study.

Dominici and his colleagues in 2006 stated that the deleterious effects of ambient PM exposures on the CVS included cardiovascular mortality, cardiac arrhythmia, myocardial infarction, myocardial ischemia and heart failure; but little attention has been given to the effects of occupational exposures which differ from general ambient exposures in particle type, exposure frequency, duration and intensity or concentration. These differences might have implications on how occupational PM exposures impact CVD and how these associations are studied.

Alarge study performed on construction workers by Toren and colleagues in 
2007 revealed a significantly increased risk of IHD. When evaluated by type of particulate exposure, increased risk of IHD was observed in association with inorganic dust, fumes and diesel exhaust particles.

Fang and his colleagues in 2010 reviewed 697 observational studies cited in PubMed and Embase that investigated the association between particulate exposures in the workplace and cardiovascular outcomes. They found that occupational PM exposure was associated with decreased heart rate variability, IHD mortality and MI. Also, they found that intense exposures might act as an acute trigger of acute coronary events for individuals with preexisting CVD. Findings from this review justified a greater recognition of the risk of both the development and aggravation of CVD from occupational exposure to PM.

\section{Effects of exposure to Nitrates:}

Exposure to nitrates occurs mainly in motor industry as mixture between solvents and nitrates (dinitrotoluene) also fumes of nitrogen oxide generated during welding operations and in construction industry during blasting.

In our study, this effect is evident in higher incidence of coronary events in Motor and Construction Industries when compared to Food Industry (Table 2). Also, results revealed very highly significant increase in number of total in-patient, $\mathrm{CCU}$ admission, in addition to interventional coronary procedures in the 2 industries when compared to Food Industry (Table 3).

Nitrates exposure was known to exert their acute effects as arterial vasodilators causing headache among regularly exposed workers. Two types of acute cardiac effects have been described; rebound coronary vasospasm occurring several days following cessation of exposure which can result in myocardial ischemia and necrosis, dysrhythmias and sudden death and possibly by paradoxical occurrence of dysrhythmias on re-exposure after a period away from work typically on Monday or after vacations (Fine and Rosenstock 2005).

Tchounwou and his colleagues in 2003 studied the health effects of exposure to dinitrotoluene (DNT) and found that one of the primary targets of DNT toxicity is the CVS (IHD).

Case reports of acute myocardial infarction due to coronary vasospasm secondary to industrial nitroglycerine withdrawal was recorded by Przybojewski and Heyns in 1983 who postulated

that the infarction was directly attributable to coronary vasospasm provoked by industrial nitroglycerin 
withdrawal syndrome, since there was no evidence of any other non-atheromatous etiological factor.

\section{Effects of exposure to solvents}

In our study, workers are exposed to a variety of solvents in both Motor and Construction Industries (Table 6). In Motor Industry, solvents are used as cleaners, degreasers, in spray paints, in coatings and thinners or in paint removers. In Construction Industry, solvents are used as varnishes, paints, adhesives, cleaners, in paint strippers.

Fine and Rosenstock in 2005 stated that solvent exposure could expose workers to several forms of cardiac affection including dysrhythmias, hypertension, cardiomyopathy and CAD.

Dysrhythmias were recorded to occur on acute exposure to high levels, caused by sensitization of the myocardium to endogenously secreted catecholamines. Other factors included physical, psychological and thermal stress. The agents of concern are organic solvents, with both halogenated (particularly fluorocarbons) and non-halogenated chemicals.

In accordance Kauffman and colleagues in 1994 described two cases of atrial fibrillation and one case of sudden death in workers exposed to the solvent trifluoro- trichloroethane. This agent and related halogenated hydrocarbons widely used in industry have been previously linked to ventricular arrhythmias and cardiac sudden death when inhaled in excessive concentrations. They suggested that occupational overexposure to halogenated hydrocarbons should be considered a potential precipitant for atrial as well as ventricular arrhythmias.

Methylene chloride (solvent used in paint stripper) exerts its cardiotoxicity through metabolic conversion to carbon monoxide $(\mathrm{CO})$. $\mathrm{CO}$ binds to hemoglobin with a resultant decrease in tissue oxygenation delivery. Also, it binds to the cytochrome oxidase system in the mitochondria of cardiac muscle and thereby directly decrease myocardial contractility; in addition to increased platelet adhesiveness (Fine and Rosenstock 2005).

In argue with these results an old study done by Hearne and Pifer in 1999 who found that mortality caused by long-term exposure to methylene chloride was below expectation for all causes of death, IHD and cancer.

Our study was challenging to target comparing three different industries which are widespread across the country and affecting wide strata of young Egyptian males. 
In addition, workers in these industries were exposed to mixture of hazardous substances in addition to other contributing physical and psychological factors.

Furthermore, certain occupational factors were shown to aggravate or attenuate other risk factors; a condition that makes interpretation of different factors separately a matter of complicated issue.

Several studies searched effects of combined exposures. Attarchi and colleagues in 2013 studied combined effects of exposure to occupational noise and mixed organic solvents on blood pressure in car manufacturing company workers. Results indicated that each factor alone might be associated with the prevalence of hypertension and that combined exposure has an additive effect in this regard.

On the contrary, Chang and his colleagues in 2009 found that simultaneous exposure to noise and a mixture of organic solvents might have a sub-additive effect on the risk of hypertension.

Regarding combined exposure to occupational noise and shift working on blood pressure, Attarchi and his colleagues in 2012 found that shift working and simultaneous exposure to noise have an additive effect on occurrence of hypertension.

\section{Conclusion}

There is substantial increase in number of premature Coronary artery diseases (CAD) diagnosed among young Egyptian male workers (the age of the studied group ranges between 18-45 years old) associated with increased admissions due to complicating events and growing demand for coronary interventions by balloon dilatation, stent deployment and coronary artery bypass surgeries. We used to expect those events in relatively older age but early detection in the age of 30's in our study might be attributable to the occupational environment which might be co-responsible for earlier aggravation of the pathological processes of atherosclerosis which is potentially geno-environmentally determined and encountering inflammatory and immune mechanisms that should be subjected to more research.

Different industries might vary in the incidence of coronary events and complications due to local environmental factors and variable exposures.

Minimizing exposure to physical, psychological, chemical and environmental factors would be a prime requirement for primary, secondary and tertiary prevention of IHD in these young workers. 
Industrial safety measures used depending upon traditionally known exposures, need to be tailor made and updated.

\section{Recommendations}

Research on CVD and work can play an important part in the development of integrated prevention in the next century.

Integrated prevention at the worksite should include the following 3 different prevention strategies:

i. environmental intervention (reduction of harmful exposures at work),

ii. worksite health promotion (focusing on individual life-style and resources),

iii. rehabilitation at the worksite (focusing on those employees who have (had) a disease).

If these 3 strategies of prevention are combined, the positive effects of each one will tend to strengthen the others.

Our recommendations are based on:

Pre-employment check- up and periodic medical examination of workers with careful occupational history that should focus on eliciting possible exposures to known or suspected occupational cardiovascular toxins or risk factors.
Safety appliances to avoid exposure to noise and solvents and air pollutants. At the same time efforts must be directed towards reducing solvent content in paints.

Noise reduction by engineering, administrative or work practice controls.

Non- smoking campaigns should be promoted among young workers.

Patients with traditional risk factors for CVD should be advised not only to take the best lifestyles to promote their health but to receive the secondary preventive measures for treating their overlapping risk factors.

Cooperation between general practitioners, occupational diseases specialists \& cardiologists may improve the efficiency of prevention programs.

Successful preventive strategies necessitate an assessment of risk, to categorize patients, for selection of appropriate intervention.

\section{Limitations of this study}

Limitations are represented by the multiplicity of the studied factors to which workers are exposed also to a complex area of human behavior and biology.

Poverty, a known risk factor for stress and its complications is an unavoidable determinant. 
It was difficult to compare our results with other studies, because we could not find studies that specifically examined such complex cardiovascular risk models as a dependent variable on a sample of young, healthy individuals, and most of previous studies were targeting one industry at a time.

It is often difficult to differentiate between the impact of the working environment and the impact of other risk factors that occur outside working hours.

Overestimation may have occurred as a result of inadequate control for confounders.

\section{References}

1. Attarchi M, Golabadi M, Labbafinejad Y and Mohammadi S (2013): Combined effects of exposure to occupational noise and mixed organic solvents on blood pressure in car manufacturing company workers. Am J Ind Med; 56(2):243-51.

2. Attarchi M, Dehghan F, Safakhah F, Nojomi M and Mohammadi S (2012): Effect of exposure to occupational noise and shift working on blood pressure in rubber manufacturing company workers. Ind Hlth; 50(3):205-13.

3. Attia DI, Abdelghafar H and Zahra A (2004): Impact of chronic noise exposure on stress response, cardiovascular system and auditory system among Marble and Granite workers. Egyp J Occup Med; 28(2): 327- 44.

4. Backe EM, Seidler A, Latza U, Rossnagel K and Schumann B (2012): The role of psychosocial stress at work for the development of cardiovascular diseases: a systematic review. Int Arch Occup Environ Hlth; 85:67-79.
5. Berglund $\mathrm{B}$, Lindvall $\mathrm{T}$ and Schwela $\mathrm{DH}$ (2000): Guidelines for Community Noise. Geneva: WHO.

6. CDC (2012): Vital signs: awareness and treatment of uncontrolled hypertension among adults-United States, 2003-2010. MMWR; 61(35): 703-9.

7. Chang TY, Wang VS, Hwang BF, Yen HY, Lai JS, Liu CS and Lin SY (2009): Effects of co-exposure to noise and mixture of organic solvents on blood pressure. J Occup Hlth; 51(4):332-9.

8. Diène E, Fouquet A and Esquirol Y (2012): Cardiovascular diseases and psychosocial factors at work. Arch Cardiovascular Disease;105: 33- 9.

9. Dominici F, Peng RD, Bell ML, Pham L, McDermott A, Zeger SL and Samet JM (2006): Fine particulate air pollution and hospital admission for cardiovascular and respiratory diseases. JAMA; 295: 1127-34.

10. Fang SC, Cassidy A and Christiani DC (2010): A Systematic Review of Occupational Exposure to Particulate Matter and Cardiovascular Disease. Int J Environ Res Public Hlth; 7: 1773806.

11. Fine LJ and Rosenstock L (2005): Cardiovascular disorders. In: Rosenstock L, Cullen MR, Brodkin CA, Redlich CA, eds. Textbook of Clinical Occupational and Environmental Medicine. 2ndEd. Philadelphia: Elsevier; Chap.24:p. 549-64.

12. Fogari R, Zoppi A, Corradi L, Marasi G, Vanasia A and Zanchetti A (2001): Transient but not sustained blood pressure increments by occupational noise. An ambulatory blood pressure measurement study. J Hypert; 19 (6):1021-7.

13. Greiser KH, Kluttig A, Schumann B, Kors JA, Swenne CA, Kuss O, Werdan K and Haerting J (2005): Cardiovascular disease, risk factors and heart rate variability in the elderly general 
population: Design and objectives of the cardiovascular disease, Living and Ageing in Halle (CARLA) Study. BMC Cardiov Disord; 5:33.

14. Hearne FT and Pifer JW (1999): Mortality study of two overlapping cohorts of photographic film base manufacturing employees exposed to methylene chloride. J Occup Environ Med; 41(12):1154-69.

15. Juel K, Sørensen J, Brønnum-Hansen $H$ et al (2008): Risk factors and public health in Denmark. Occupational accidents. Scand J Pub Hlth; 36(1): 152-7.

16. Kaufman JD, Silverstein MA and Moure-Eraso $R$ (1994): Atrial fibrillation and sudden death related to occupational solvent exposure. Am J Ind Med; 25(5):731-5.

17. Kip KE, Hollabaugh K, Marroquin OC and Williams DO (2008): The problem with composite end points in cardiovascular studies: The story of major adverse cardiac events and percutaneous coronary intervention. J Am College Card; 51: 701-7.

18. Kivimaki M, Virtanen $M$, Elovainio $M$ et al (2006): Work stress in the etiology of coronary heart di8ease-a meta-analysis. Scand J Work Environ Hlth; 32: 431 - 42.

19. Kivimaki M, Leino-Arjas P, Luukkonen $\mathrm{R}$, Riihimäki $\mathrm{H}$, Vahtera $\mathrm{J}$ and Kirjonen $\mathrm{J}$ (2002): Work stress and risk of cardiovascular mortality: prospective cohort study of industrial employees. BMJ; 325: 857-60.

20. Leather P, Beale D and Sullivan L (2003): Noise, psychosocial stress and their interaction in the workplace. J Environ Psychol; 23: 21322.

21. Liu L (2007): Cardiovascular diseases in China. Biochem Cell Biol; 85(2): 157-63.

22. Minh HV, Byass P and Wall S (2003): Mortality from cardiovascular diseases in Bavi District, Vietnam. Scand J Pub Hlth; 31(62): 26-31.

23. Murray CJ and Lopez AD (1997): Global mortality, disability and contribution of risk factors: Global Burden of Disease study. Lancet; 349: 1436 - 42 .
24. Netterstrøm B and Kristensen TS (2005): Psychosocial factors at work and ischemic heart disease. Ugeskr Laeger; 167(46):4348-55.

25. Niemann H, Bonnefoy X, Braubach M, Hecht K, Maschke C, Rodrigues C and Röbbel N (2006): Noise-induced annoyance and morbidity results from the pan/European LARES study. Noise Hlth; 8:9-32.

26. Obelenis V and Malinauskiene V (2007): The influence of occupational environment and professional factors on the risk of cardiovascular disease Medicina (Kaunas); 43(2):96-102.

27. Pinto A, Nunes IL and Ribeiro RA (2011): Occupational risk assessment in construction industry - Overview and reflection. Safety Science; 49: 616-24.

28. Prasad DS, Kabir Z, Dash AK and Das BC (2010): Cardiovascular risk factors in developing countries: A review of clinicoepidemiological evidence. CVD Prevention and Control; 5: 115-23.

29. Przybojewski JZ and Heyns MH (1983): Acute myocardial infarction due to coronary vasospasm secondary to industrial nitroglycerin withdrawal. A case report. S Afr Med J; 16:101-4.

30. Rasul F, Stansfeld SA, Hart CL and Davey Smith G (2005): Psychological distress, physical illness, and risk of coronary heart disease. J Epidemiol Comm Hlth; 59:140-5.

31. Sahai H and Khurshid A (1996): Statistics in epidemiology: methods, techniques, and applications. Boca Raton, FL: CRC Press, Inc.

32. Sharman JE, Coombes JS, Geraghty DP and Fraser DI (2002): Exposure to automotive pollution increases plasma susceptibility to oxidation. Arch Environ Hlth; 57(6):536-40.

33. Tchounwou PB, Newsome C, Glass K, Centeno JA, Leszczynski J, Bryant J, Okoh J, Ishaque A and Brower M (2003): Environmental toxicology and health effects associated with dinitrotoluene exposure. Rev Environ Hlth; 18(3):203-29. 
34. Timothy DN, Allan MJ, Matthew WG and Loren EW (2012): Direct and indirect effects of particulate matter on the cardiovascular system. Toxicol Lett; 208(3): 293- 9.

35. Tsutsumi A, Kayabab K and Ishikawa S (2011): Impact of occupational stress on stroke across occupational classes and genders. Social Science \& Medicine; 72: 1652-8.

36. Toren K, Bergdahl IA, Nilsson T and Jarvholm B (2007): Occupational exposure to particulate air pollution and mortality due to ischemic heart disease and cerebrovascular disease. Occup Environ Med; 64: 515-9.
37. World Health Organization (1998): Fifty years of the WHO in the Western Pacific Region. Report of the Regional Director to the Regional Committee for the Western Pacific Region, Manila.

38. Yan LL, Liu K, Matthews KA, Daviglus ML, Ferguson TF and Kiefe CI (2003): Psychosocial factors and risk of hypertension: the coronary artery risk development in young adults (CARDIA) study. JAMA; 290 (16): 2138-48.

39. Yang W and Omaye ST (2009): Air pollutants, oxidative stress and human health. Mutation Research; 674 (1-2): 45-54. 